\title{
Meeting The Need For Special Education Teachers For Culturally Linguistically Diverse Students With Disabilities
}

Patricia Peterson, Northern Arizona University, USA

Stephen Showalter, Northern Arizona University, USA

\begin{abstract}
This paper describes why special education teachers are needed to meet the needs of the increasing number of culturally and linguistically diverse students with disabilities in the United States. The paper presents innovative approaches to recruiting and training culturally responsive special education teachers.
\end{abstract}

\section{RATIONALE FOR TEACHER PREPARATIONS PROGRAMS}

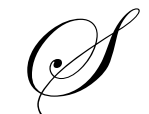

ignificant personnel shortages in special education have been noted in the 23rd Annual Report to Congress on the Implementation of IDEA Act (USDE, 2002). With predictions of even more serious teacher shortages, there is an especially critical need for additional special education teachers for students with disabilities from culturally and linguistically diverse backgrounds in rural areas (USDE, 2002). In addition, the current emphasis on providing nondiscriminatory assessment procedures and assessing the effectiveness of multicultural instructional programs is drawing attention to the efficacy of traditional special education and general education teacher training programs which typically do not offer systematically integrated coursework and practicum experiences specific to the multicultural characteristics of students with disabilities (Baca \& Cervantes, 2004; Gallegos \& McCarty, 2000; Gollnick \& Chinn, 2006; Salend, 2004; Stuart \& Parette, 2002.)

\section{RESPONSE TO THE PROBLEM}

In response to the need for special education teachers in rural areas with high numbers of Culturally and Linguistically Diverse Exceptional (CLDE) students, four innovative programs (PRISE, DREAMS, BRIDGE, and BEST) and a Bilingual Multicultural Special Education Website have been developed to serve rural areas of Arizona. Through technology, we have overcome the barriers involved with pursuing university study for rural students. This is especially important for Native American students who live in very remote reservation areas, do not have running water, chop wood for cooking and heat, power their lights and home computers with a generator, and must drive 50 miles on dirt roads to their local school teaching jobs.

\section{IMPACT OF TECHNOLOGY AND THE GRANT PROGRAMS}

The Bilingual Multicultural Special Education website has been developed as a component of four Federal Education Grants (PRISE, DREAMS, BRIDGE, BEST) for the purpose of disseminating information about each Grant including Culturally Diverse Special Education lesson plans and Powerpoint Training of Trainers presentations developed by culturally diverse students in the grant classes. The URL for the Grant programs main web site is: www4.nau.edu/clde

One website component is a database of student developed Native American culturally relevant special education lesson plans. The lesson plan database URL is: http://www4.nau.edu/clde/lessonplans/ 
PRISE, DREAMS, BRIDGE, and BEST participants develop lessons that not only teach a specific concept but also address the cultural and linguistic diversity of the local student population and design accommodations for any individual special education needs. In many cases, effective strategies which have been used successfully with the general population of students with disabilities can easily be adapted to fit the needs of English Language Learners (ELL) and Culturally and Linguistically Diverse Exceptional (CLDE) students. Student lessons are posted on the program Website to enable not only the program students to exchange and utilize each other's lessons, but also to enable others in far reaching diverse rural communities all over the world to access and download these culturally relevant lessons. Students in the five programs follow a Direct Instruction Lesson Plan Rubric which emphasizes direct linking of cultural context and language background of the CLDE students to the objectives, content, and learning mode of the lesson. The Lesson Plan Rubric URL is: http://www4.nau.edu/clde/lessonplans/

Modifications for students with disabilities in the general education classroom and integration of technology are clearly linked to the goals and objectives of the lesson. Examples of culturally relevant thematic lessons developed by students include: Native American Basketry (Art, Math, History, Science), Las Hormiguitas (Ants - Ant Multiplication, Ant Families, Life Cycle, ANTonyms), Sheep and Wool (Native American Families, traditions, economics, math), and Celebrations (Pinata, Birthdays, Math, Families).

Educators interested in obtaining these culturally relevant Special Education lesson plans can search the lesson plans database by Culture, Language (Spanish or Navajo), Grade (K - 12) or the Grant program with which the lesson plan is associated. From these four categories the lessons plans are divided by content area. Once a content area is chosen, the database user can view a brief description of the Special Education lesson plan and then choose to view, print, and/or save the entire lesson plan in Adobe Acrobat PDF format.

Training of Trainers (TOT) Utilizing Microsoft Powerpoint is taught in the grant programs. The capstone course in these programs has a culminating assignment requiring students to prepare and participate in delivery of a TOT module. Students receive training in Powerpoint which they use to develop their training workshops. The Culturally Diverse Powerpoint training presentations developed by the students are included in the Grant Website so that educators worldwide can benefit from this Professional Development CLDE Training. Grant students then utilize the TOT model to deliver this Professional Development Training in which 400 additional peer teachers from the consortium districts receive training in best practice strategies for working with ELL and CLDE students. Grant students not only receive training, but they also become the future district trainers in the area of best practice for teaching ELL and CLDE students. This training is also available on the Bilingual Multicultural Special Education Website.

\section{USE OF DISTANCE EDUCATION TECHNOLOGY}

In these programs, distance education technology (Grant Website, Web-based courses, Email feedback to and from instructors, and Instructional Interactive Television -IITV) maximize the utilization of the resources of the university's main campus while allowing the students in these rural areas to remain in their local communities to complete their coursework.

There has been considerable interest in the potential advantages of the use of computer-based technology in education. Charp (2000) maintains that a number of observations can be safely made:

- $\quad$ Students are becoming freed from the physical boundaries of classrooms and the time restrictions of schedules.

- $\quad$ Students are working at their own pace using network-based materials and diagnostic tools.

- Dynamic databases are emerging that permit students, faculty and administrators to have 24-hour access to financial records, student transcripts, class lectures, assignments, etc. over the Internet.

Through interaction in Web-based courses, university students learn teamwork, group decision-making, and problem identification and problem-solving (Synder, 2000). The goal according to Snyder (2000) with Interactive Group Software is to get students involved in old-fashioned interactivity - human interaction - instead of just clicking buttons on a computer screen. This research influenced the design of the Web courses in PRISE, 
DREAMS, BRIDGE, and BEST. The Web-based courses in these four programs have been designed to include a high degree of group interaction, reflection, and feedback from one student to another as well as between the instructor and the students.

A major focus of another study (Hill \& Hannafin, 1997) was the World Wide Web (WWW). This study reported that some prior knowledge and experience in open learning applications, helping learners to construct a functional mental model of the system, and providing searching tips, should increase their chances of success in web-based courses. According to Hill and Hannafin (1997), preliminary interpretations indicate that teaching the strategies for finding information in open information systems like the WWW is prerequisite for success. In light of these findings, all of the PRISE, DREAMS, BRIDGE, and BEST students receive intensive training in the use of technology systems including word processing, email, Web Searches, and specific Web course access, utilization, and pedagogy.

Additionally, Email provides communication between faculty and students in these four programs. For example, in BRIDGE, which involves internship supervision for teachers who are completing certification in Special Education via this program, the participant is in e-mail contact with the university supervisor each week during the semester. The email serves as a medium for the participant to ask questions, get feedback on ideas for lessons (including management and problem solving), and generally maintain a high level of rapport between the university internship supervisor and the BRIDGE participants. The email also serves as a way to help the participants incorporate what they are learning in their content classes with the daily routine in their own classrooms. The university internship supervisor is aware of what content classes the BRIDGE participant is taking and what the requirements of the content classes include. This knowledge of the content classes coupled with knowledge of the participant's own classroom is invaluable and strengthens the quality of the individual feedback communicated via email.

Another technology approach used in these programs is teaching the courses via a satellite microwave link Interactive Instructional Television System (IITV). Instructors deliver the course from one of the TV classroom sites, and the students receive the class at their local rural site. State of the art technology transmits and receives courses at sites throughout Arizona. Students in electronic classrooms in Yuma and Tuba City see the instructor at the home site electronic classroom and vice versa. Students and faculty converse and interact in discussion activities just as if they were in the same classroom.

\section{DESCRIPTION OF PROGRAMS}

Preparing Rural Inclusive Special Educators (PRISE) serves the needs of schools in rural areas with high populations of English Language Learners (ELL) by working with the school districts in the Yuma area of Arizona to train paraprofessionals to become elementary and special education teachers of ELL students. Yuma is a very rural, agricultural area on the border of Mexico with many newly arrived ELL students in the schools. Some districts have over $90 \%$ ELL students.

Developing Rural Exceptional-educators to Address Multicultural Students (DREAMS) is designed to prepare special education teachers to meet the culturally and linguistically diverse needs of Native American and Mexican-American students with disabilities and their families especially those living in rural and remote areas (Peterson \& Showalter, 1999).

Bilingual Rural Inclusive Development for General and Exceptional-educators (BRIDGE) prepares Masters Degree special educators to work in rural schools with a high percentage of culturally and linguistically diverse student populations. These areas also have a shortage of individuals certified to work with children with disabilities. Coursework for the entire Masters Degree in Special Education with an emphasis in Bilingual Special Education is delivered through a distance technology approach combined with on-site face-to-face courses. Major goals are to train potential leaders in the field of Culturally and Linguistically Diverse Exceptional (CLDE) Learners, utilize a Trainer of Trainers (TOT) model to deliver additional Professional Development training in CLDE inclusive strategies, and to develop and disseminate via Website the culturally and linguistically appropriate curriculum materials. 
Bilingual/ESL Special-education Training (BEST) is the reverse degree program of BRIDGE in that BEST is a Masters Degree program in Bilingual Multicultural Education and then similarly includes a focus on CLDE student identification, assessment, methods, and materials. This program model illustrates how a graduate program in general education (Bilingual Multicultural Education) can creatively incorporate coursework in best practices for assessing and teaching rural CLDE students. As a result, general educators become knowledgeable in teaching culturally diverse students with disabilities in the general education classroom. BEST works with rural schools in the Yuma area on the border of Mexico and includes Culturally Relevant Lessons and TOT training on the Grant Website.

\section{AUTHOR INFORMATION}

Patricia Peterson is a Professor of Special Education at Northern Arizona University. She received her Ph.D. in Special Education with a minor in Bilingual Education from the University of Florida. Her work centers on improving services for culturally and linguistically diverse exceptional (CLDE) students. She has directed bilingual special education teacher training projects including doctoral programs with a focus on CLDE students. She has developed rural programs in special education on the Navajo Reservation and border areas of the Southwest and provided technical assistance and training in this field to school districts and state departments of education.

Stephen Showalter is an Instructor in the Department of Teaching and Learning at Northern Arizona University where he teaches Web-based courses in Curriculum and Instruction and Secondary Education. His doctorate is in Curriculum and Instruction from Northern Arizona University. His dissertation was titled "Student Assessment in Web-based Instruction". His research focus is in the area of development and assessment of Web-based courses. He is also Webmaster, Web Curriculum Developer, and Technology Facilitator for federally funded personnel preparation grants. He taught Biology and Earth Science on the Navajo Reservation where he worked with Native American high school students.

\section{REFERENCES}

1. Baca, L., \& Cervantes, H. (2004). The bilingual special education interface. (4th ed.). Columbus, OH: Merrill.

2. $\quad$ Charp, S. (2000). The role of the Internet. Technology Horizons in Education, 27 (7), 8-9.

3. Gallegos, A., \& McCarty, L. (2000). Bilingual multicultural special education: An integrated preparation program. Teacher Education and Special Education, 23 (4), 264-270.

4. Gollnick, D. M., \& Chinn, P. (2006). Multicultural education in a pluralistic society ( $7^{\mathrm{h}}$ ed.). Columbus, $\mathrm{OH}$ : Merrill.

5. Hill, J., \& Hannafin, M. (1997). Cognitive strategies and learning from the world wide web. Educational Technology Research and Development, 45 (4), 37-64.

6. Peterson, P., \& Showalter, S. W. (1999. September). Issues and solutions in field based programs with Native American and Mexican American students in rural areas. Paper presented at the 1999 Conference of the Arizona Educational Research Association, Flagstaff, AZ.

7. Salend, S. (2004).Creating inclusive classrooms: Effective and reflective practices. Columbus, OH: Merrill.

8. Snyder, T. (2000). Snyder Productions [Online] Available http://www.teachtsp.com/ [2000].

9. Stuart, S., \& Parette, H.P. (2002). Native Americans and Augmentative and Alternative Communication Issues. Multiple Voices, 5 (1), 38-53.

10. U.S. Department of Education (2002). Designated Teacher Shortage Area. Available http: http://www.ed.gov/offices/OPE/Students/repayment/teachers/tsa.html [2002]. 